\title{
Genetic Variation Among and Within Populations in Swedish Species of Sorbus aucuparia L. and Prunus padus L. Assessed in a Nursery Trial
}

\author{
By V. BALIUCKAS ${ }^{1, *}$, T. LAGERSTRÖM ${ }^{2}$, L. NORELL ${ }^{3}$ and G. ERIKSSON ${ }^{4}$
}

(Received 22 $2^{\text {nd }}$ September 2004)

\begin{abstract}
Seedlings originating from open-pollinated offspring of six and four populations of Prunus padus and Sorbus aucuparia, respectively, were studied with respect to phenology and growth traits for 3-4 years in a nursery. There were no replications at the population levels since the experiments should be converted to seedling seed orchards. Therefore, a special statistical model for analysis of the population effect was developed making use of neighbour performances. This model was also used for derivation of heritabilities. The heritabilities for phenology traits were in many cases high in $P$. padus, $>0.40$, while they varied in the range 0.07-0.62 in $S$. aucuparia. The population effect was significant for all growth rhythm traits in $P$. padus and for a majority of traits in S. aucuparia. In both species the heritability for height decreased over time. Only bud flushing in $P$. padus indicated a relationship with population latitudinal origin in some cases. The genetic correlations between bud flushing different years were relatively strong in both species while the corresponding correlations for leaf colouring were moderate in P. padus and weak in $S$. aucuparia. In conclusion, the observed structure suggests that the pattern of seed dispersal may have an influence on the among- and within-population variation.
\end{abstract}

Key words: P. padus, S. aucuparia, populations, half-sib families, nursery experiments, juvenile age, adaptive traits, growth rate, genetic variation.

\section{Introduction}

The increasing concern on commercially less important species, as for instance Sorbus spp. and Prunus spp., during the last decades in European countries made it possible to initiate new projects which enables enlargement of genetic knowledge on them (see proceedings of Noble Hardwoods Network of European Forest Genetic Resources Programme - EUFORGEN). The creation of proper conditions for gene conservation is hardly possible without the knowledge of evolutionary processes in forest tree species (ERIKSSON et al., 1993).

\footnotetext{
1) Department of Genetics and Breeding, Lithuanian Forest Research Institute, LT-53101 Girionys, Kaunas distr. Lithuania.

2) Department of Landscape Planning, Swedish University of Agricultural Sciences, Box 7012, SE-750 07 Uppsala, Sweden.

3) Department of Biometry and Engineering, Swedish University of Agricultural Sciences, Box 7032, SE-750 07 Uppsala, Sweden.

4) Department of Plant Biology and Forest Genetics, Swedish University of Agricultural Sciences, Box 7080 SE-750 07 Uppsala, Sweden

*) Communicating author: e-mail: virgis.baliuckas@takas.lt Phone: +370 37 547289, Fax: +370 37547446 .
}

The genetic knowledge available on rare forest tree species is still scarce.

Sorbus aucuparia and Prunus padus both have more or less the same geographic distribution in Sweden from the very north to the south, but they do not always overlap and belong to the same type of vegetation or tree communities. Both species have a wide but scattered distribution, both are insect pollinated (though not the same species compositions of insects), good seed dispersal by birds and mammals. They differ with respect to time of seed maturation, Sorbus aucuparia has such a late seed maturation that migrating birds may cause a considerable southwards seeds transfer while there is high probability that $P$. padus seeds are distributed locally by birds thanks to an earlier seed maturation than in S. aucuparia. If this difference were of greatest significance, the among-population variation would be larger in $P$. padus than in $S$. aucuparia. The ability to resprout from stump or roots also is characteristic to both species. The main differences in life history traits between the two species are the successional stage in forest ecosystems and outcrossing rate: $S$. aucuparia being normally a pioneer species (but also with high shade tolerance at young age) and to some extent selfpollinated, while $P$. padus is intermediate and predominantly outcrossing, but with occurring efficient vegetative regeneration (DEILLER et al., 2003). At higher altitudes $S$. aucuparia can become the species present in all succession stages (Kullman, 1986). Based on northern population investigation SPERENS (1997) found that $S$. aucuparia is only partly self-incompatible, though the situation could be different in central part of the species natural distribution range. Apomictic reproduction way is quite usual in Sorbus species, but not in S. aucuparia (SPERENS, 1997). The process of natural hybridization between the Swedish Sorbus species (there are also naturally occurring $S$. intermedia, $S$. hybrida) can result in a hybrid complex (PROCTOR et al., 1989), which complicates the taxonomy in agreement with the situation after species hybridization in oak species (RUSHTON, 1993).

The higher altitudinal range of Sorbus aucuparia is another characteristic that separates the two species. One more peculiarity of this species is the usually high intensity browsing pressure on the seedlings that keeps them under canopy layer for a long time even if they occur abundantly in cohorts. If present, this causes the physiological senescence and reduces the period of reproductive longevity of mature trees. $P$. padus trees commonly inhabit richer and wetter soils than $S$. aucuparia. Even if both species are hardy with respect to climatic conditions and characterised by high adaptedness, 
this does not necessarily mean that they experience the same kind of environmental heterogeneity (LEVINS, 1963) as they have different reaction norms. The size of selective environmental neighbourhood in sensu BRANDON (1990) can differ in the two species as well. STERN (1961) has shown that even closely related forest tree taxa could differ much in ecological requirements if they differ with respect to succession stage in forest ecosystem. LEVIN (1963) predicted that climax species are more specialized than pioneer species. Intermediate species in that case would be somewhat in between. Species with wide range of distribution should be exposed to large heterogeneity in habitats.

The objectives of the study were to study the pattern of variation for climatic adaptation within and between populations. We also intended to investigate if any differences in genetic structure may be related to differences in life history traits.

\section{Material and Methods}

Open-pollinated families of trees from six Swedish native populations of $P$. padus and four populations of $S$. aucuparia were studied in a common garden experiment. Trees with superior phenotype as regards growth and stem quality were selected for seed collection, keeping a distance of approximately 40 meters between them in order to decrease the possibility that they are components of the same clones. The geographic data of the populations and the number of open-pollinated families in each population are presented in Table 1. The selected populations cover only parts of the whole species range in Sweden.

Table 1. - Geographical data of the sampled populations.

\begin{tabular}{llllll} 
No. Population (location) & $\begin{array}{c}\text { Number of } \\
\text { families }\end{array}$ & N. Latitude E. Longitude Altitude m a.s.1. \\
\hline & $\begin{array}{l}\text { Sorbus aucuparia: } \\
1\end{array}$ Röddinge & 6 & $55^{\circ} 34^{\prime}$ & $13^{\circ} 49^{\prime}$ & 110 \\
2 & Svenneby & 6 & $58^{\circ} 31^{\prime}$ & $11^{\circ} 19^{\prime}$ & $15-30$ \\
3 & Rättvik & 6 & $60^{\circ} 52^{\prime}$ & $15^{\circ} 05^{\prime}$ & $165-175$ \\
4 & Omneberget & 6 & $62^{\circ} 56^{\prime}$ & $18^{\circ} 21^{\prime}$ & $150-200$ \\
& & & & & \\
& Prunus padus: & & & & \\
1 & Eahagen & 9 & $58^{\circ} 25^{\prime}$ & $13^{\circ} 40^{\prime}$ & $140-160$ \\
2 & Skållerud & 7 & $59^{\circ} 30^{\prime}$ & $13^{\circ} 10^{\prime}$ & 80 \\
3 & Ultuna & 9 & $59^{\circ} 53^{\prime}$ & $17^{\circ} 34^{\prime}$ & 12 \\
4 & Billudden & 9 & $60^{\circ} 34^{\prime}$ & $17^{\circ} 26^{\prime}$ & $10-20$ \\
5 & Rättvik & 10 & $60^{\circ} 52^{\prime}$ & $15^{\circ} 05^{\prime}$ & $165-175$ \\
6 & Omneberget & 10 & $62^{\circ} 56^{\prime}$ & $18^{\circ} 21^{\prime}$ & $20-50$ \\
\hline
\end{tabular}

The seeds of $P$. padus were collected in 1992 and $S$. aucuparia in 1993. The stratification of seeds was done before sowing. The nursery trial was established in Pustnäs nursery, 7 kilometers south of Uppsala, on sandy loamy soil in autumn 1993 with $P$. padus and in autumn 1994 with $S$. aucuparia one-year-old seedlings. The experiment was designed so that one population was kept in a separate block with six replications of randomised four-tree plots per family at a spacing of $1 \mathrm{x}$ $1.2 \mathrm{~m}$ between trees. The reason for keeping the populations separated from each other was that the trial should be able to convert into seedling seed orchard. Six families in $S$. aucuparia and 7-10 families in P. padus represented each population.

The recordings were collected in three subsequent years starting at age 3, though some traits were recorded four years and phenology traits were assessed several times per season. With exception of height and leader length, the traits were recorded in classes with linear scales. The traits assessed for both species were: bud flushing (0-5), leaf autumn colouring (0-4), or leaf fall (0-5), plant health/conditional status (0-2) and height. In addition to this, amount of flowers or flowering abundance (0-3) and the stage of flower development or flower status (0-3) were assessed in $P$. padus. The growth after a repeated flush was recorded in $S$. aucuparia: 0 - no reflushing, 1 - start to reflush, 2 - long leader of repeated flush. The higher the figure the more advanced the stage of trait progress, e.g. leaf development and colour intensity, with the exception of plant status where the higher number stays for poorly performing plants. The recordings were made up to age 5 in both species and only two traits were assessed in P. padus at age 6 .

\section{Statistical Methods}

Individual observations were used in the analyses. The parameters were estimated using the procedure Mixed of the SAS Software (1999).

The spatial variation was modelled in two parts. A latent surface as a function of the row and column numbering was used for the longitudinal trends of the field conditions. The local dependence was modelled by a random field where the correlation between plots decreases with the distance. The purpose with these techniques was to adjust the comparisons of the unreplicated populations.

The model for an observation $y_{r c}$ of the tree in row $r$ and column $c$ was:

$$
y_{r c}=\mu+p_{i(r c)}+f_{i j(r c)}+w_{k l(r c)}+d_{r c}+e_{r c}
$$

where

$\mu=$ overall mean,

$p_{i(r c)}=$ effect of population $i$,

$f_{i j(r c)} \sim N\left(0, \sigma_{f}^{2}\right)$, random effect of family $j$ within population $i$,

$$
\begin{aligned}
& w_{k l(r c)} \sim N\left(0, \sigma_{w}^{2}\right), \text { random effect of plot } k l, \\
& d_{r c}=\frac{\left[g_{s s}\left(r_{u}-r\right)+g_{u s}\left(r-r_{s}\right)\right]\left(c_{u}-c\right)+\left[g_{s u}\left(r_{u}-r\right)+g_{u u}\left(r-r_{s}\right)\right]\left(c-c_{s}\right)}{\left(r_{u}-r_{s}\right)\left(c_{u}-c_{s}\right)}
\end{aligned}
$$

for $r_{s}<r<r_{u}, c_{s}<c<c_{u}$

$e_{r c} \sim N\left(0, \sigma_{e}^{2}\right)$, residual error.

The subscript notations $i(r c), i j(r c)$, and $k l(r c)$ indicate that, for given row and column coordinates, the corresponding population, family, and plot, respectively, are identified from the field plan. The coordinates of the four-tree plots were calculated as $k=[(r+1) / 2]$ and $l=[(c+1) / 2]$ where [ ] denotes the integer part. The correlation between two plots is modelled by the anisotropic power structure

$$
\rho\left(w_{k l}, w_{m n}\right)=\rho_{r}{ }^{|k-m|} \rho_{c}^{|l-n|} \quad-1<\rho_{r}<1,-1<\rho_{c}<1
$$


The latent field effect $d_{r c}$ is a weighted average of the effects $g_{s s}, g_{u s}, g_{s u}$ and $g_{u u}$ at the corner points $\left(r_{s}, c_{s}\right),\left(r_{u}\right.$, $\left.c_{s}\right),\left(r_{s}, c_{u}\right)$, and $\left(r_{u}, c_{u}\right)$, respectively. The weights are inversely proportional to the coordinate-wise distances. The corner points were used to define subareas. The subareas for $P$. padus were chosen as shown by large dots in Figure 1.

As two neighbour subareas share two corner points, the latent surface is continuous all over the field. Within a subarea and for a given value of $r$, the latent surface is linear in $c$ but the slope depends on $r$. The same characterization is true with $r$ and $c$ interchanged. Due to these linear properties, the field effect at the center point of a population is obtained as a weighted mean of the effects $g_{s s}, g_{u s}, g_{s u}$ and $g_{u u}$ at the corner points. As an example, the latent field effect for the $P$. padus population no. 5 (latitude $60^{\circ} 52^{\prime}$ ) with center point $(8.5,36.5)$ is written

$\underline{\left[g_{s s}(16.5-8.5)+g_{u s}(8.5-0.5)\right](62.5-36.5)+\left[g_{s u}(16.5-8.5)+g_{u u}(8.5-0.5)\right](36.5-28.5)}$ $(16.5-0.5)(62.5-28.5)$

that simplifies to $\left\{\left[g_{s s}+g_{u s}\right] 13+\left[g_{s u}+g_{u u}\right] 4\right\} / 34$ with $g_{s s}$, $g_{u s}, g_{s u}$ and $g_{u u}$ as the effects at $(0.5,28.5),(16.5,28.5)$, $(0.5,62.5)$, and $(16.5,62.5)$, respectively. The field plan for $S$. aucuparia was a square with plants in 24 rows and 24 columns. The four populations were placed in squares of size $12 \times 12$. The whole field was used as a subarea for the $d_{r c}$ structure using the corner points $(0.5,0.5),(24.5,0.5),(0.5,24.5)$, and $(24.5,24.5)$. Hypotheses of latent horizontal field effect were tested by $F$ statistics.

One effect of this spatial modelling is that neighbour populations are compared with a better precision than those more apart. This is mainly a consequence of the latent surface, unless the correlation parameters $\rho_{r}$ and $\rho_{c}$ are very close to 1 .

In model (2) below the connected effects $d_{r c}$ in model (1) are replaced by separate regression planes for each population.

$$
y_{r c}=\mu+p_{i(r c)}+f_{i j(r c)}+w_{k l(r c)}+\alpha_{i} r+\beta_{\mathrm{i}} c+e_{r c}
$$

The random variation is the same in the models but there is no requirement in model (2) making the regression planes to meet between neigbouring populations.

The residual effects $e_{r c}$ of individual trees were assumed to be independent. The plot variance was included in the phenotypical variance and the formula used for the narrow-sense heritability was:

$$
h_{a}^{2}=\frac{4 \sigma_{f}^{2}}{\sigma_{f}^{2}+\sigma_{w}^{2}+\sigma_{e}^{2}}
$$

and the estimate was found by replacing the variance components by their estimates from Proc Mixed, SAS (1999). As $d_{r c}$ was used for the spatial effect, there were no block effects included in the model. Standard errors of the estimates of the heritabilities and the relative variance components were found by Taylor expansions and the asymptotic covariance matrix of the estimates obtained from Proc Mixed. Individual heritabilities by using separate family variance components for the populations were also obtained (in addition to the pooled versions in model (1)). In order to check whether the family variance components were different among populations, the likelihood ratio test with the $\chi^{2}$ statistic was used. The likelihoods for the models with a common family variance and for separate variances were found by REML using Proc Mixed.

Additive genetic coefficients of variation for each population was calculated using the formula:

$$
C V_{A}=\frac{\sqrt{4 \cdot \hat{\sigma}_{f}^{2}}}{\hat{\mu}} 100
$$

Genetic correlations based on pooled data from all populations were calculated. Correlations were calculated only if the standard error of the family variance component was less than $60 \%$ of the estimate of the component. The calculated types of genetic correlations were: 1) correlations between the same trait assessed in two

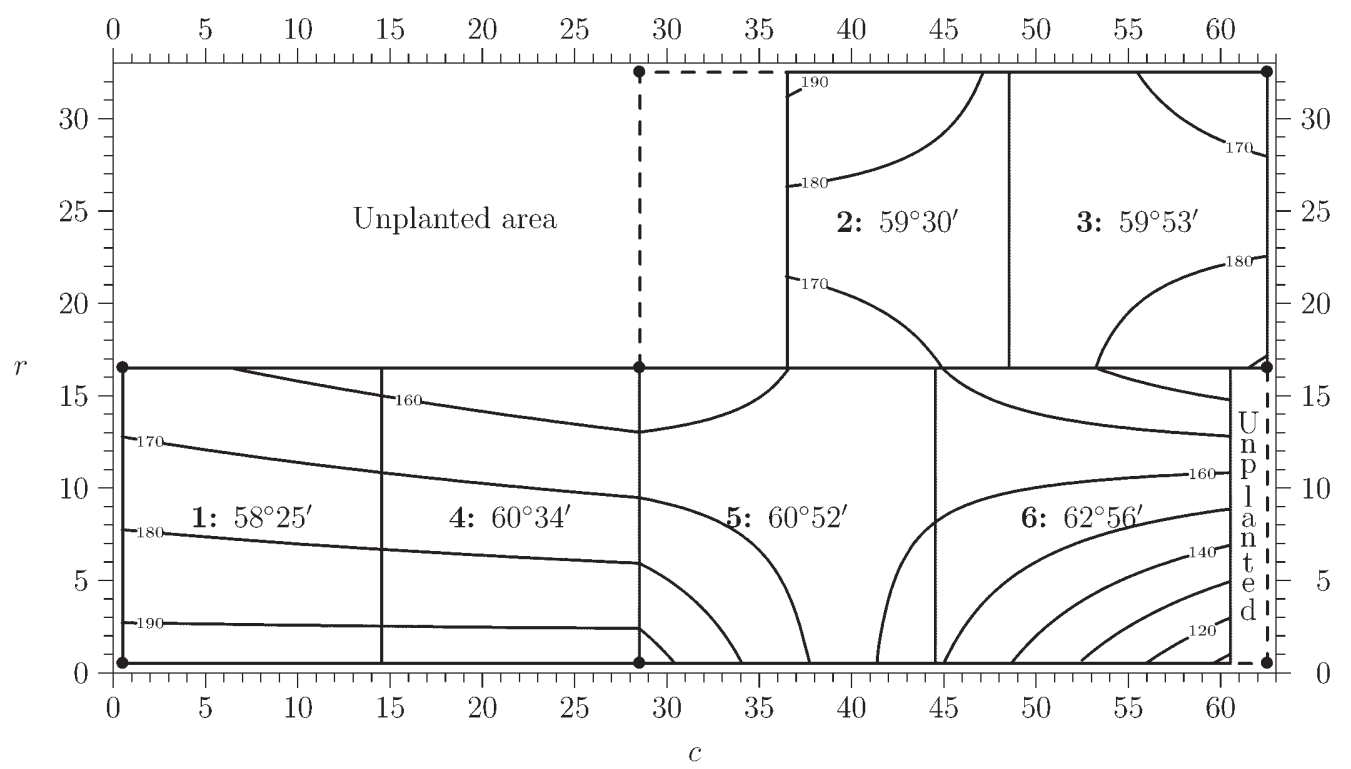

Figure 1. - Field plan for Prunus padus. Corners for subareas are marked with large dots. Estimated latent field levels $110, \ldots, 190$ for height at age 5 are shown. 
or more years; 2) correlations between different traits assessed in a specific year. For calculations of genetic correlation coefficients the set of programs "Dfprep" and "Dxmux" of DFREML Software $3.0 \propto$ (MEYER, 1997) was used. In this program, block effect was set as fixed and no covariables or additional random effects were used in calculation of genetic correlations.

\section{Results}

The estimate of the spatial latent surface corrected for population effects is illustrated in Figure 1 for the height at age 5 of $P$. padus. The field conditions were most favorable for population no. 1 (lat. $58^{\circ} 25^{\prime}$ ) in the left part of the field whereas the situation is the opposite for population no. 6 (lat. $62^{\circ} 56^{\prime}$ ) in the lower right corner. The first line of Table 2 shows uncorrected effects of the populations determined by using local disconnected regression planes separately for each population. The corrected effects on the second line are based on model (1). The differences on the third line are similar to the estimated center-point field effects. The latter can also be discerned in Figure 1 by subtracting the estimate 170.8 of the overall height mean at age 5 . The local model (2) with regression planes is used to enable similar estimation of the variance components for plots and trees. For the height at age 5 , the estimates of $\sigma_{w}^{2}$ were 274.3 (standard error 87.1) for the local model (2) and 236.9 (s.e. 62.7) for model (1). The estimates of the variance component for individual trees were 989.8 (s.e. 44.2) and 986.8 (s.e. 43.9). The estimated correlation parameters in model (1) for the height at age 5 in P. padus were $\hat{\rho}_{r}=0.44$ (s.e. 0.14 ) and $\hat{\rho}_{c}=0.44$ (s.e. 0.09 ). The correlations are significantly different from zero but as the variation between plots is small compared to that for individual trees, $\sigma_{w}^{2} / \sigma_{e}^{2}=236.9 / 986.8=0.24$, the influence is limited to some but not unessential adjustment for the precision in the comparison of population effects. One consequence of the spatial adjustments is that the precision of the population comparisons decreases with the distance. One example was for the height at age 4 where the difference $21.2-(-3.2)=24.4$ between the effects of populations nos. 4 (lat. $60^{\circ} 34^{\prime}$ ) and 5 (lat. $60^{\circ} 52^{\prime}$ ) was significant (adjusted with respect to 15 possible pair-wise comparisons) but the difference $21.2-(-5.3)=26.5$ of population nos. 4 (lat. $60^{\circ}$ $34^{\prime}$ ) and 6 (lat. $62^{\circ} 56^{\prime}$ ) was not in spite of the larger difference.

Table 2. - Effects for height at ages 4 and 5 of Prunus padus. Population effects without and with adjustment for field effects in the local model (2) and model (1), respectively. Effects with the same letter ( $a$ or b) are not significant in pair-wise comparisons, where the level used is $0.05 / 15=0.0033$ corrected for 15 possible pairs.

\begin{tabular}{lcccccc}
\hline \multicolumn{1}{c}{ Population } & 1 & 2 & 3 & 4 & 5 & 6 \\
\hline Height at age 5 & & & & & & \\
Local model (2) & 21.5 & -22.6 & -10.4 & 42.5 & -6.1 & -25.0 \\
Model (1) & $15.1 a b$ & $-26.9 b$ & $-16.2 b$ & $37.8 a$ & $-2.2 b$ & $-7.6 b$ \\
Difference & 6.4 & 4.3 & 5.8 & 4.7 & -3.9 & -17.4 \\
Field effect & 6.2 & 5.5 & 5.6 & 3.4 & -4.2 & -16.5 \\
Height at age 4 & & & & & & \\
Model (1) & $7.2 a b$ & $-12.5 b$ & $-7.4 a b$ & $21.2 a$ & $-3.2 b$ & $-5.3 a b$ \\
\hline
\end{tabular}

Table 3. - Spatial effects for Prunus padus: $F$ test of constant field effect and estimates of spatial parameters in model (1). Number of * indicate significant results at levels $0.05,0.01$ and 0.001 of the $F$ test and when testing $\sigma_{w}^{2}=0, \rho_{r}=0, \rho_{c}=0$. Spatial correlations are shown only when significance is obtained for $\sigma_{w}^{2}$.

\begin{tabular}{lllll}
\hline Trait (measuring date) & Field effects & $\hat{\sigma}_{w}^{2} / \hat{\sigma}_{e}^{2}$ & $\hat{\rho}_{r}$ & $\hat{\rho}_{c}$ \\
\hline Bud flushing at age 3 (19 Apr) & $5.41^{* * *}$ & 0 & - & - \\
Bud flushing at age 3 (04 May) & 1.27 & 0 & - & - \\
Bud flushing at age 4 (30 Apr) & 0.60 & $0.12^{* *}$ & 0.38 & $0.79^{* * *}$ \\
Bud flushing at age 4 (13 May) & $2.34^{*}$ & 0.04 & - & - \\
Bud flushing at age 5 (18 Apr) & 0.63 & 0.03 & - & - \\
Bud flushing at age 5 (06 May) & 1.08 & 0 & - & - \\
Leaf colouring at age 3 & $2.41^{*}$ & $0.07 *$ & 0.19 & $0.73^{* * *}$ \\
Leaf fall at age 3 (03 Oct) & 0.77 & 0.08 & - & - \\
Leaf fall at age 3 (10 Oct) & 1.69 & 0.03 & - & - \\
Leaf fall at age 5 (24 Sep) & $5.62^{* * *}$ & $0.07^{*}$ & $-0.65^{*}$ & $0.45^{*}$ \\
Leaf fall at age 5 (08 Oct) & $2.81^{* *}$ & $0.08^{* *}$ & 0.29 & $0.58^{* * *}$ \\
Flowering at age 6 & $2.41^{*}$ & 0.04 & - & - \\
Flower status at age 6 & $2.27^{* *}$ & $0.06^{*}$ & 0.16 & $0.79^{* * *}$ \\
Height at age 2 & 1.10 & $0.06^{*}$ & -0.16 & $0.81^{* * *}$ \\
Height at age 3 & $3.83^{* * *}$ & 0.14 & - & - \\
Height at age 4 & $5.00^{* * *}$ & $0.11^{*}$ & $0.53^{*}$ & $0.84^{* * * *}$ \\
Height at age 5 & $3.21^{* *}$ & $0.24^{* * *}$ & $0.44^{* *}$ & $0.74^{* * *}$ \\
Leader length at age 3 & $3.62^{* * *}$ & 0.17 & - & - \\
Leader length at age 4 & $3.70^{* * *}$ & $0.11^{* *}$ & $0.54^{* * *}$ & $0.56^{* * *}$ \\
Leader length at age 5 & $2.93^{* *}$ & $0.24^{* * *}$ & $0.48^{* * * *}$ & $0.72^{* * * *}$ \\
Status at age 4 & $2.06^{*}$ & $0.08^{*}$ & 0.32 & $0.86^{* * *}$ \\
\hline
\end{tabular}

Table 4. - Spatial effects for Sorbus aucuparia: $F$ test of constant field effect and estimates of spatial parameters in model (1). Number of * indicate significant results at levels $0.05,0.01$ and 0.001 of the $F$ test and when testing $\sigma_{w}^{2}=0, \rho_{r}=0, \rho_{c}=0$. Spatial correlations are shown only when significance is obtained for $\sigma_{w}^{2}$.

\begin{tabular}{lllll}
\hline Trait (measuring date) & Field effects & $\hat{\sigma}_{w}^{2} / \hat{\sigma}_{e}^{2}$ & $\hat{\rho}_{r}$ & $\hat{\rho}_{c}$ \\
\hline Bud flushing at age 3 (30 Apr) & 0.86 & 0.15 & - & - \\
Bud flushing at age 3 (13 May) & $6.45^{* * *}$ & $0.12^{*}$ & -0.16 & 0.01 \\
Bud flushing at age 3 (14 May) & $2.79^{*}$ & 0.05 & - & - \\
Bud flushing at age 4 (07 May) & $4.30^{* *}$ & 0.01 & - & - \\
Bud flushing at age 4 (13 May) & $4.16^{* *}$ & 0 & - & - \\
Leaf colouring at age 2 & 0.18 & $0.24^{*}$ & $0.74^{* * *}$ & $0.45^{*}$ \\
Leaf fall at age 3 & 0.23 & 0.07 & - & - \\
Leaf fall at age 4 & $7.17^{* * *}$ & $0.10^{*}$ & 0.08 & $0.57^{* *}$ \\
Height at age 2 & 1.78 & $0.17^{* *}$ & 0.36 & 0.20 \\
Height at age 3 & $2.93^{*}$ & $0.21^{* *}$ & $0.64^{* * *}$ & $0.43^{*}$ \\
Height at age 4 & 1.09 & $0.37^{* * *}$ & $0.64^{* * *}$ & $0.43^{* *}$
\end{tabular}

Summaries of the results for the field effects analysed by model (1) are given for $P$. padus and $S$. aucuparia in Tables 3 and 4. Most of the significant different field effects and significant spatial correlation occurred for the height and growth traits in P. padus.

The population effect was strongly significant for most traits in $P$. padus, except for flower stage, flowering abundance, and plant status (Table 5). Similarly, plant status in $S$. aucuparia did not show significance for the population effect but contrary to the situation in $P$. padus there were no or weak significant estimates 
Table 5. - Means, heritabilities, $\chi^{2}$ tests of homogeneous family variances, $F$ tests of population effects, and $\mathrm{CV}_{\mathrm{A}}$ estimates in Prunus padus. Estimates of $h_{a}^{2}$ and $\mathrm{CV}_{\mathrm{A}}$ are pooled over all populations.

\begin{tabular}{lrrrrr}
\hline Trait (measuring date) & Mean & $h_{a}^{2}$ & $\chi^{2}$ & $F$ test & $\mathrm{CV}_{\mathrm{A}}$ \\
\hline Bud flushing at age 3 (19 Apr) & 2.1 & $0.17 \pm 0.07$ & $* * *$ & $9.31^{* * *}$ & 7.0 \\
Bud flushing at age 3 (04 May) & 3.6 & $0.49 \pm 0.12$ & & $15.28^{* * *}$ & 11.5 \\
Bud flushing at age 4 (30 Apr) & 2.3 & $0.21 \pm 0.08$ & & $12.67 * * *$ & 9.1 \\
Bud flushing at age 4 (13 May) & 3.6 & $0.45 \pm 0.11$ & & $11.20^{* * *}$ & 7.9 \\
Bud flushing at age 5 (18 Apr) & 1.8 & $0.62 \pm 0.14$ & $* * *$ & $4.75^{* *}$ & 17.2 \\
Bud flushing at age 5 (06 May) & 3.5 & $0.57 \pm 0.13$ & & $10.03 * * *$ & 14.0 \\
Leaf colouring at age 2 & 0.9 & $0.26 \pm 0.09$ & & $18.20^{* * *}$ & 24.3 \\
Leaf fall at age 3 (03 Oct) & 1.0 & $0.12 \pm 0.95$ & & $6.13 * * *$ & 23.2 \\
Leaf fall at age 3 (10 Oct) & 2.1 & $0.48 \pm 0.12$ & & $10.83^{* * *}$ & 19.4 \\
Leaf fall at age 5 (24 Sep) & 2.4 & $1.11 \pm 0.19$ & $* * *$ & $14.82^{* * *}$ & 31.3 \\
Leaf fall at age 5 (08 Oct) & 3.7 & $0.82 \pm 0.16$ & $* * *$ & $14.45^{* * *}$ & 12.6 \\
Flowering at age 6 & 1.7 & $0.38 \pm 0.10$ & & 1.64 & 38.7 \\
Flower status at age 6 & 2.1 & $0.36 \pm 0.10$ & & $2.49 *$ & 32.4 \\
Height at age 2 & 31.7 & $0.95 \pm 0.17$ & $* * *$ & $21.15^{* * * *}$ & 18.2 \\
Height at age 3 & 61.8 & $0.35 \pm 0.10$ & & $3.44 * *$ & 13.8 \\
Height at age 4 & 109.9 & $0.31 \pm 0.09$ & & $4.10^{* * *}$ & 12.1 \\
Height at age 5 & 170.8 & $0.24 \pm 0.08$ & & $5.70^{* * * *}$ & 9.9 \\
Leader length at age 3 & 30.0 & $0.13 \pm 0.06$ & & $10.43^{* * *}$ & 15.9 \\
Leader length at age 4 & 48.3 & $0.20 \pm 0.08$ & & $8.77 * * *$ & 11.8 \\
Leader length at age 5 & 62.4 & $0.16 \pm 0.07$ & & $4.08^{* *}$ & 10.5 \\
Status at age 4 & 0.2 & $0.18 \pm 0.07$ & $*$ & $2.61 * *$ & - \\
\hline
\end{tabular}

Table 6. - Means, heritabilities, $F$ tests of population effects, and $\mathrm{CV}_{\mathrm{A}}$ estimates in Sorbus aucuparia. Estimates of $h_{a}^{2}$ and $\mathrm{CV}_{\mathrm{A}}$ are pooled over all populations. Likelihood ratio $\chi^{2}$ test did not show significance for different heritabilities among populations.

\begin{tabular}{lrccr}
\hline Trait (measuring date) & Mean & $h_{a}^{2}$ & $F$ test & $\mathrm{CV}_{\mathrm{A}}$ \\
\hline Bud flushing at age 3 (30 Apr) & 2.6 & $0.18 \pm 0.11$ & $8.42^{* * *}$ & 8.9 \\
Bud flushing at age 3 (13 May) & 3.9 & $0.40 \pm 0.18$ & $5.54^{* *}$ & 12.3 \\
Bud flushing at age 3 (14 May) & 4.4 & $0.26 \pm 0.13$ & $5.19^{* *}$ & 7.7 \\
Bud flushing at age 4 (07 May) & 2.7 & $0.57 \pm 0.20$ & $9.81^{* * *}$ & 18.6 \\
Bud flushing at age 4 (13 May) & 3.8 & $0.57 \pm 0.20$ & $11.04^{* * *}$ & 15.2 \\
Leaf colouring at age 2 & 1.3 & $0.07 \pm 0.10$ & 2.42 & 23.4 \\
Leaf fall at age 2 & 2.2 & $0.08 \pm 0.09$ & $15.92^{* * * *}$ & 6.2 \\
Leaf fall at age 3 & 2.3 & $0.31 \pm 0.20$ & $4.46^{*}$ & 11.0 \\
Leaf fall at age 4 & 1.3 & $0.62 \pm 0.22$ & 1.02 & 58.4 \\
Height at age 2 & 46.0 & $0.45 \pm 0.20$ & $5.71^{* *}$ & 25.4 \\
Height at age 3 & 87.4 & $0.39 \pm 0.17$ & $5.11^{* *}$ & 16.3 \\
Height at age 4 & 130.6 & $0.19 \pm 0.12$ & $5.46^{* *}$ & 10.4 \\
\hline
\end{tabular}

Table 7. - The linear relationship between population effects in Prunus padus and latitudinal origin. Determination coefficient and observed significance level $(P)$ when testing horizontal slope.

\begin{tabular}{lrrrrrrrrrr}
\hline Trait & \multicolumn{3}{c}{ At age 3 } & \multicolumn{4}{c}{ At age 4 } & \multicolumn{3}{c}{ At age 5 } \\
\cline { 2 - 12 } & Slope & $\mathrm{R}^{2}$ & $P$ & Slope & $\mathrm{R}^{2}$ & $P$ & Slope & $\mathrm{R}^{2}$ & $P$ \\
\hline Bud flushing, 1st observation & 0.05 & 0.17 & 0.42 & 0.08 & 0.21 & 0.36 & 0.05 & 0.31 & 0.25 \\
Bud flushing, 2nd observation & 0.19 & 0.57 & 0.09 & 0.19 & 0.65 & 0.05 & 0.16 & 0.55 & 0.09 \\
Leaf fall, 1st observation & 0.09 & 0.35 & 0.21 & - & - & - & -0.25 & 0.29 & 0.28 \\
Leaf fall, 2nd observation & -0.01 & 0 & 0.95 & - & - & - & -0.16 & 0.18 & 0.40 \\
Height & -3.54 & 0.28 & 0.28 & -0.90 & 0.01 & 0.83 & -0.97 & 0 & 0.91 \\
Leader length & 1.56 & 0.10 & 0.55 & 2.05 & 0.18 & 0.40 & 0.20 & 0 & 0.96 \\
\hline Flowering at age 6 & -0.08 & 0.16 & 0.43 & & & & & & \\
Flower status at age 6 & 0.09 & 0.14 & 0.46 & & & & & & \\
\hline
\end{tabular}

obtained for most leaf fall and leaf colouring traits (Table 6).

Our data show that there is a large variation for phenology and growth traits in some populations. These differences are reflected in the relatively high estimates of heritability and $\mathrm{CV}_{\mathrm{A}} \mathrm{s}$ for these populations. Generally, the heritability and $\mathrm{CV}_{\mathrm{A}}$ estimates were rather similar in the two species but the standard errors in $P$. padus were somewhat smaller (Tables 5 and 6 ). With respect to $\mathrm{CV}_{\mathrm{A}}$ estimates of individual populations, leaf fall and leaf coloring were the traits that varied mostly among the traits studied. The heritability of the phenology traits of $P$. padus and $S$. aucuparia increased with age and became remarkably high for leaf fall (Tables 5 and 6 ) while the estimates decreased with age for height.

The results of the likelihood ratio test for homogeneous family variances among the populations were non-significant for $S$. aucuparia, but significant for almost one third of the traits in P. padus (Tables 5 and 6 ). The pooled estimates of heritabilities based on a common family variance were used in Tables 5 and 6 , irrespective of the results of the $\chi^{2}$ test.

As seen from Table 7 there were positive relationships between bud flushing and latitude for assessments carried out in $P$. padus. All other relationships with other types of trait were weak with low values of $R^{2}$. With only four populations it was not meaningful to try to trace any clinal relationship with origin of the populations in $S$. aucuparia. However, the two southerly populations grew much better than the two northerly populations.

From Tables 8 and 9 it is seen that the genetic correlations between leaf colouration in different years was rather weak while the corresponding correlations for bud flushing were mostly strong. Autocorrelation

Table 8. - Prunus padus. In bold extreme values of genetic correlation coefficients for the withintrait correlations over years are given. In normal font extreme values for correlations between different types of traits assessed specific year are presented. In case of only one estimate possible, the estimate is given as a maximum.

\begin{tabular}{|c|c|c|c|c|c|c|c|c|}
\hline \multirow[t]{2}{*}{ Group of traits } & \multicolumn{2}{|c|}{ Bud flushing } & \multicolumn{2}{|c|}{ Leaf colouring } & \multicolumn{2}{|c|}{ Height } & \multicolumn{2}{|c|}{ Leader length } \\
\hline & $\min$ & $\max$ & $\min$ & $\max$ & $\min$ & $\max$ & $\min$ & $\max$ \\
\hline Bud flushing & $0.54 \pm 0.10$ & $0.83 \pm 0.06$ & $-0.12 \pm 0.05$ & $0.04 \pm 0.12$ & $-0.31 \pm 0.11$ & $0.61 \pm 0.08$ & $-0.33 \pm 0.20$ & $0.34 \pm 0.09$ \\
\hline Leaf colouring & & & $0.35 \pm 0.06$ & $0.56 \pm 0.09$ & $-0.34 \pm 0.10$ & $-0.21 \pm 0.09$ & $-0.35 \pm 0.18$ & $0.11 \pm 0.15$ \\
\hline Height & & & & & $0.69 \pm 0.07$ & $0.97 \pm 0.01$ & $0.90 \pm 0.02$ & $0.93 \pm 0.02$ \\
\hline Leader length & & & & & & & - & $0.71 \pm 0.18$ \\
\hline
\end{tabular}


Table 9. - Sorbus aucuparia. In bold extreme values of genetic correlation coefficients for the within-trait correlations over years are given. In normal font extreme values for correlations between different types of traits assessed specific year are presented. In case of only one estimate possible, the estimate is given as a maximum.

\begin{tabular}{lcccccc}
\hline Group of traits & \multicolumn{2}{c}{ Bud flushing } & \multicolumn{2}{c}{ Leaf colouring } & \multicolumn{2}{c}{ Height } \\
\cline { 2 - 6 } & min & $\max$ & $\min$ & $\max$ & \multicolumn{1}{c}{$\min$} & $\max$ \\
\hline Bud flushing & $\mathbf{0 . 6 8} \pm \mathbf{0 . 1 7}$ & $\mathbf{0 . 9 4} \pm \mathbf{0 . 0 3}$ & $-0.11 \pm 0.14$ & $0.11 \pm 0.10$ & $-0.43 \pm 0.13$ & $0.04 \pm 0.13$ \\
Leaf colouring & & & $\mathbf{0 . 1 0} \pm \mathbf{0 . 1 1}$ & $\mathbf{0 . 3 5} \pm \mathbf{0 . 1 3}$ & $-0.34 \pm 0.12$ & $-0.09 \pm 0.11$ \\
Height & & & & & $\mathbf{0 . 8 6} \pm \mathbf{0 . 0 8}$ & $\mathbf{0 . 9 6} \pm \mathbf{0 . 0 3}$ \\
\hline
\end{tabular}

explains to a large extent the strong height-height correlations.

In both species the genetic correlations between different types of traits were all relatively weak and sometimes negative.

\section{Discussion}

\section{Variation within populations}

The individual heritability and $\mathrm{CV}_{\mathrm{A}}$ estimates for the phenological traits are to some extent dependent on the stage of development at the assessment. If the assessments take place very early or very late there will not be possible to reveal genetic variation. In the present material there are only a few indications that heritability estimates are low owing to low mean values (Tables 5 and 6 ).

We have assumed that the material studied consisted of true half-sibs. As a consequence of this the family variance estimates a quarter of the additive variance. SÆвø and JoHNSEN (2000) assumed that there was a higher degree of relatedness in their Sorbus aucuparia study. They assumed that the family variance estimated one third of the additive variance. Since the two species occur scattered there is some probability that pollinations take place mainly within small cohorts of trees giving room for a certain degree of full-sibs. As a corollary of this, heritability and $\mathrm{CV}_{\mathrm{A}}$ estimates may be overestimated. However, it is impossible to know the relatedness within the open-pollinated progenies and therefore our estimates must be regarded as upper limits for heritability and $\mathrm{CV}_{\mathrm{A}}$. In this way estimations beyond the allowed values, as was the case for one of the leaf fall estimates in P. padus (Table 5) and for height in population no. 1 of $P$. padus, may be attributed to a higher degree of relatedness than half-sibs. It should also be noted that the relatively low number of families makes the precision of the estimates fairly low. Even if the estimates are somewhat exaggerated they must be regarded as surprisingly high for this category of species. This large within-population variation in the two species suggests that there are effective means for gene flow even in insect pollinated and scattered tree species in agreement with the observation for Acer platanoides (ERIKSson et al., 2003) and the rarely occurring species, Sorbus torminalis, (DEMESURE et al., 2000).

The $\mathrm{CV}_{\mathrm{A}}$ estimates of the same trait at several occasions in individual populations were rather stable with a possible exception for leaf fall in some cases (data not shown). This observation is reflected in the strength of the genetic correlation coefficients (Tables 8 and 9).

Since the estimates for heritability and $\mathrm{CV}_{\mathrm{A}}$ were mostly of similar magnitude in the 2 species (cf Tables 5 and 6 ) there is no support for the expectation of a strong genetic impact of migrating birds (cf Introduction).

The estimates of heritability and $\mathrm{CV}_{\mathrm{A}}$ varied in the same range for the same type of traits as observed for another insect pollinated species, Prunus avium, studied in nursery by BALIUCKAS et al. (2000).

The observed slight increase with age for the phenological trait heritabilities and the decrease of height heritability agreed with the results reported by АжB $\varnothing$ and JOHNSEN (2000) in their study of Sorbus aucuparia. A similar age trend was observed in $P$. padus too. The decrease with age of the two parameters for height in $P$. padus may be attributed to the onset of fruiting, which led to a levelling of tree heights (cf . Sжвø and JoHNSEN, 2000).

\section{Variation among populations}

There were some differences in site conditions in the nursery trial, in which the populations were growing separated from each other. In spite of that, population differences were revealed for most traits in both species (Tables 5 and 6).

The statistical evaluations given in Tables 5 and 6 show that the population differentiation had stronger significances in $P$. padus than in $S$. aucuparia, which is in agreement with the expectation according to the difference in seed dispersal of the two species (cf Introduction). However, it should be noted that the number of populations was larger in P. padus than in S. aucuparia, which may partly contribute to this result. A wide seed dispersal by migrating birds in $S$. aucuparia as stated in Introduction will reduce the among-population variation in this species. As the tests were adjusted for the spatial effects, they were performed with a somewhat lower efficiency compared to a randomised design, in particular for populations that are planted at a long distance from each other. Adjustments as illustrated in Table 2 for the height at age 5 in the $P$. padus experiment are in some cases quite large. In particular, the field conditions are most unfavourable for population no. 6 (lat. $62^{\circ} 56^{\prime}$ ). This implies that the observed lowest mean for this population becomes the third smallest after the adjustment. Although the field differences are significant $\left(F=3.21^{* *}\right.$ in Table 3), the differences of the populations are significant after the adjustment $\left(F=4.08^{* *}\right.$ in Table 5). As a whole, the differences among populations were larger than those among field effects as indicated by the mostly weaker significances in Tables 3 and 4 compared to those in Tables 5 and 6 . The latent surface can be somewhat improper as its contours are hyperbolic and a local maximum or minimum cannot be attained within the subarea. However, as it is defined in segments it is more flexible than for example a second-order regression surface as the latter must be symmetric on both sides at long distances from the stationary point. In our P. padus data for the height at age 5 , the favourable field conditions at population no. 1 (lat. $58^{\circ} 25^{\prime}$ ) and poor condi- 
tions at population no. 6 (lat. $62^{\circ} 56^{\prime}$ ) would imply high values for population no. 3 (lat. $59^{\circ} 53^{\prime}$ ) and low for no. 2 (lat. $59^{\circ} 30^{\prime}$ ) if a second-order surface had been used. This is not realistic as seen from Figure 1. It is possible for our data to define smaller subareas and thereby more segments that can describe the latent surface. However, preliminary analyses showed that the more detailed models did not change the conclusions; the patterns such as in Figure 1 were on the whole unchanged. The continuity of the latent surface is of course important and separate non-connected regressions are not useful, see Table 2 where the unadjusted and adjusted population effects are different. In conclusion it can be stated that even after correction for the field conditions the population effects were significant for most traits in both species. The ranking, however, among the populations can be changed.

The few cases of a moderate and positive relationship between bud flushing and origin confirm the general trend from tree species that northerly populations flush earlier than southerly populations (MORGENSTERN, 1996). Even if the corresponding relationships for height were non-significant the negative slope of these relationships are in agreement with observations for trees from the same area of distribution (e.g. Eiche, 1966). In a limited material (population sizes 4-15 trees) of $S$. aucuparia BARCLAY and CRAWFORD (1984) found that the growth rate increased with altitude, which is contrary to expectation. The varying type of relationship for leaf fall suggests that this trait is of less adaptive significance than bud flushing. This agrees with observations made for Quercus robur (BALIUCKAS et al., 2001). In this connection it is worth mentioning that SÆBø and JoHNSEN (2000) explained the reduced growth of $S$. aucuparia starting from age 6 by onset of fruiting. HÅBJøRG (1978) reported conflicting data on the photoperiodic influence on growth cessation in Norwegian $S$. aucuparia populations. However, he concluded that there is a clinal variation in this species as well and that the deviating data were attributed to technical problems with light regulation in one experiment. It is evident that leaf fall in the two northerly populations of $S$. aucuparia was slightly more advanced than in the two southerly populations in agreement with HÅBJøRG's conclusion.

From the observations of plant status it is evident that the two southerly populations were healthier. Even if the northerly populations are far from marginal, it may be speculated that there is some inbreeding in seed collected from populations from harsh growth conditions. The negative correlation between the altitude of origin and seed viability and weight (see BARCLAY and CRAWFORD, 1984) suggests not only that the origin influences the duration of the growth period of trees, but also a higher rate of self-pollination in higher altitudes owing to fewer pollinators and that poorly growing trees do not attract pollinators as was shown by SPERENS (1996). In our study the populations from the highest altitude also had the poorest performance. The limiting factor of resources available at high altitudes also cannot be excluded. Popov (1990) detected a decreasing south-north cline for flower/fruit ratio in populations of $S$. aucuparia originating from White Sea to Black Sea in
Russia, and it was explained by the main influence of weather conditions of the previous year at the origins of the populations.

Based on the study of 10 loci encoding 6 enzymes in 17 European S. aucuparia populations, RASPE and JACQUEMART (1998) found quite low level of population differentiation, which was remarkably lower than wind-pollinated late successional species. Geographic pattern of isolation by distance was observed in that study, which means comparatively higher regional similarity in population groups. The founder events, such as number of contributing individuals and number of groups involved during the phase of population establishment or difference in age groups can lead to significant differences between the populations (see e.g. WHITLOCK and MCCAUley, 1990). A study of intra-specific chloroplast DNA variation of French and Belgian populations of $S$. aucuparia revealed low level of genetic differentiation among them, although it was higher than for nuclear markers (RASPE et al., 2000). RASPE et al. (2000) concluded that processes going on in meta populations, such as colonization and extinction, may increase among- and decrease within-population differentiation, despite of high level of gene flow in a species. Investigations done on German Sorbus species showed some specific adaptation or indication of ecotypes along altitudinal gradients (Hillebrand and RosenberG, 1996).

\section{Genetic correlations}

The strong correlations for bud flushing between different times and ages of assessment agree with observations in other hardwood tree species (BALIUCKAS et al., 1999, 2000, and 2001). These results also suggest that assessments 1-2 years are enough to get reliable data for this trait. In spite of the sometimes high estimates of heritability for leaf fall the genetic correlations for this trait were weak, which means that the family x environment interaction was important. This in turn suggests that this trait is more influenced by the environment than bud flushing.

In both species the correlations between different types of trait were in most cases weak and frequently negative (Tables 8 and 9). This suggests that different sets of genes regulate the various types of trait. Our estimates of genetic correlations between leaf colouring and height were weaker than observed for another insect pollinated tree species, Prunus avium (BALIUCKAS et al., 2000). One possible reason may be that leaf colouring in $P$. avium is of greater adaptive significance than in the two species studied by us.

\section{Concluding remarks}

There was a higher ratio of traits showing significant population differentiation in $P$. padus than in $S$. aucuparia (Tables 5 and 6 ). In both species the within-population variation were of about the same magnitude and surprisingly large for species with scattered distributions (Tables 5 and 6 ). This suggests that gene flow even in insect pollinated and scattered tree species may be considerable. The large within-population variation gives the two species good prospects for coping with 
changed environmental conditions and gene conservation can rely on selection of populations in the wild for gene conservation in situ. With the population differences revealed it would be advantageous to select all the populations studied as subpopulations of the gene resource population.

Finally, our data support the expectation that the among-population variation should be less in $S$. aucuparia than in $P$. padus owing to the gene flow caused by migrating birds in the former species.

\section{References}

Baliuckas, V., I. Ekberg, G. Eriksson and L. Norell (1999): Genetic variation among and within populations of four Swedish hardwood species assessed in a nursery trial. Silvae Genetica 48: 17-25.

Baliuckas, V., T. LAGERSTRÖM and G. ERIKSSON (2000): Within-population variation in juvenile growth rhythm and growth in Fraxinus excelsior L. and Prunus avium L. Forest Genetics 7 (3): 193-202.

Baliuckas, V., T. LAgerström and G. ERIKSson (2001): Within-population variation in juvenile growth rhythm and growth in Quercus robur L. and Fagus sylvatica L. Forest genetics 8 (4): 259-270.

Barclay, A. M., R. M. M. CRAWFord (1984): Seedling emergence in the rowan (Sorbus aucuparia) from an altitudinal gradient. J Ecol 72 (2): 627-636.

BRANDON, R. N. (1990): Adaptation and environment. Princeton, New Jersey.

Demesure, B., S. Oddou, B. Guerroue le, L. Leveque, T. Lamant, M. Vallance and B. Le Guerroue (2000): Wild service tree, a tropical-like species in temperate forests? Bulletin Technique Office National des Forets 39: 51-63.

Deiller, A. F., J. M. N. Walter and M. Tremolieres (2003): Regeneration strategies in a temperate hardwood floodplain forest of the Upper Rhine: sexual versus vegetative reproduction of woody species. Forest Ecology and Management 180 (1-3): 215-225.

Eriksson, G., G. NAmkoong and J. H. Roberds (1993): Dynamic gene conservation for uncertain futures. Forest Ecology and Management 62: 15-37.

HÅBJÖRG, A. (1978): Photoperiodic ecotypes in Scandinavian trees and shrubs. Meld Norges Landbruksh 57.

Hillebrand, K. and A. RosenberG (1996): Investigations on altitude-zone growth and ecotypes of rowan (Sorbus aucuparia). Forst und Holz 51 (7): 216-220.

Kullman, L. (1986): Temporal and spatial aspects of subalpine populations of Sorbus aucuparia in Sweden. Annales Botanici Fennici 23: 267-275.
LEvins, R. (1963): Theory of fitness in a heterogeneous environment. II. Developmental flexibility and niche selection. Am Nat 97 (893): 75-90.

MEYER, K. (1997): User Notes for Software DFREML version 3.0a.

MoRgenstern, E. K. (1996): Geographic variation in forest trees. Genetic basis and application of knowledge in silviculture. UBC Press: 209 p.

Popov, A. A. (1990): Geographical variation in Sorbus aucuparia L. Rastitel'nye Resursy 26 (2): 145-150.

Proctor, M. C. F., M. E. Proctor and A. C. Groenhof, 1989: Evidence from peroxidase polymorphism on the taxonomy and reproduction of some Sorbus populations in south-west England. New Phytol 112 (4): 569-575.

RASPE, O. and A. L. JACQUEMART (1998): Allozyme diversity and genetic structure of European populations of Sorbus aucuparia L. (Rosaceae: Maloideae). Heredity 81 (5): 537-545.

Raspe, O., P. Saumitou-Laprade, J. Cuguen and A. L. JACQUEMART (2000): Chloroplast DNA haplotype variation and population differentiation in Sorbus aucuparia L. (Rosaceae: Maloideae). Mol Ecol 9 (8): 1113-1122.

Rushton, B. S. (1993): Natural hybridization within the genus Quercus L., pp. 73-90. In: Genetics of oaks, edited by A. Kremer, P. S. Savill, K. C. Steiner, Proceedings of the first meeting of the IUFRO working party S2.02-22, Annales des Sciences Forestieres 50 (Suppl. $1)$.

SAS Institute Inc., 1999: SAS/STAT(r) User's Guide, Version 8, Cary, NC, USA.

SæBø, A. and Ø. JOHNSEN (2000): Growth and morphology differ between wind-exposed families of Sorbus aucuparia (L.). J Arboric 26 (5): 255-262.

SPERENS, U. (1996): Is fruit and seed production in Sorbus aucuparia L. (Rosaceae) pollen-limited. Ecoscience 3 (3): 325-329.

SPERENS, U. (1997): Long-term variation in, and effects of fertiliser addition on, flower, fruit and seed production in the tree Sorbus aucuparia (Rosaceae). Ecography 20: 521-534.

STERN, K. (1961): Preliminary estimates of the genetic structure of two sympatric populations of birches as determined by random effects and natural selection, pp. 25-34 in Proceedings $9^{\text {th }}$ Northeastern Tree Impr. Conf., Syracuse, NY, USA, 1961.

Whitlock, M. C. and D. E. McCauley (1990): Some population genetic consequences of colony formation and extinction: genetic correlations within founding groups. Evolution 44: 1717-1724. 